\title{
A Reappraisal of Rhythmic Coma Patterns in Children
}

\author{
Rajesh RamachandranNair, Rohit Sharma, Shelly K. Weiss, Hiroshi Otsubo, \\ Miguel A. Cortez
}

\begin{abstract}
Objective: This study was designed to determine the prevalence of rhythmic coma patterns in comatose children and to ascertain the prognostic significance of reactive rhythmic coma patterns. Methods: We retrospectively analyzed and classified electroencephalogram (EEGs) in comatose children between two months and 18 years of age during the period 1996 - 2003 according to modified Young's classification. Outcome at one-year was scored according to the Paediatric Cerebral and Overall Performance Category Scale. Outcomes were compared using Fisher's exact test and Mann-Whitney test. Results: Analysis of 63 electroencephalogram (EEG) records in 38 patients showed rhythmic patterns in 19 records (30.2\%; 9 alpha, 4 spindle, 4 theta and 2 beta coma patterns, total number of children $=14$ ). Aetiology and outcome of alpha coma patterns and other rhythmic coma patterns were similar. In five children, one type of rhythmic pattern changed to another. Records with reactive rhythmic coma $66.7 \%$ (6/9), were associated with favourable outcome. Sixty percent of the records $(6 / 10$ records in seven children) with non-reactive pattern were associated with unfavourable outcome. This clinically significant difference did not reach statistical significance (lower Paediatric Cerebral and Overall Performance Category Scale score $\mathrm{p}=0.14$; favourable outcome $\mathrm{p}=0.19$ ). Conclusion: Rhythmic coma patterns in comatose children are not uncommon. Aetiology, reactivity and outcome of individual patterns are similar and thus make the rhythmic coma patterns distinct EEG signatures in comatose children. There was a clinically significant better outcome with reactive rhythmic coma patterns.
\end{abstract}

RÉSUMÉ: Réévaluation de l'activité rythmique chez l'enfant comateux. Objectif: Cette étude a été conçue pour déterminer la prévalence de l'activité rythmique chez les enfants comateux et pour évaluer la valeur pronostique de l'activité rythmique réactive chez ces enfants. Méthodes: Nous avons analysé et classifié de façon rétrospective les ÉEG d'enfants comateux âgés de 2 mois à 18 ans entre 1996 et 2003 selon la classification modifiée de Young. L'issue à 1 an était évaluée selon la Paediatric Cerebral and Overall Performance Category Scale (PCOPCS). Les résultats ont été analysés au moyen du test de Fisher et du test de Mann-Whitney. Résultats: L'analyse de 63 ÉEGs chez 38 patients a révélé la présence d'activité rythmique dans 19 enregistrements (30,2\% dont la présence de rythme alpha chez 9, de fuseaux chez 4, de rythme thêta chez 4 et de rythme bêta chez 2 , chez 14 enfants au total). L'étiologie et l'issue du coma étaient similaires quel que soit le rythme observé. Chez 5 enfants, un type d'activité rythmique a changé pour un autre. Chez 66,7\% (6/9) des enregistrements de tracé de coma réactif l'issue a été favorable et chez 60\% (6/10 enregistrements faits chez sept enfants) ayant un tracé de coma non réactif l'issue a été défavorable. Cette différence importante au point de vue clinique n'atteignait pas le seuil de la significativité statistique (score PCOPCS plus bas $\mathrm{p}=0,14$; issue favorable $\mathrm{p}=0,19$ ). Conclusion: On observe fréquemment différents types d'activité rythmique chez les enfants comateux. L'étiologie, la réactivité et l'issue de chaque type de rythme sont similaires, ce qui confère à ces rythmes une signification ÉEG distincte chez les enfants comateux. L'issue était bien meilleure au point de vue clinique pour les rythmes de coma réactif.

Can. J. Neurol. Sci. 2005; 32: 518-523

Although alpha coma (AC) is a well-recognized EEG pattern in adults with coma, there are only a few reports of this pattern in children. ${ }^{1-11}$ Recently, the concept of rhythmic coma pattern has been expanded to include reactive EEG patterns and other frequencies like theta coma (TC). ${ }^{12-14}$ Prognosis of AC pattern is poor in adults. ${ }^{12,13,15,16}$ Survival was better in the paediatric population based on case reports of children with AC pattern. ${ }^{1-11}$ Over the last decade some authors have suggested that incomplete (reactive) AC pattern had a better outcome in adults. ${ }^{12,13,15}$ It is unclear whether incomplete $\mathrm{AC}$ in children may lead to a better outcome. Based on the observation that aetiology and outcome were similar in alpha, theta, spindle and beta coma, it was proposed that the pathophysiology of these patterns in children might be the same as alpha coma in adults, i.e., the interruption of the reticulothalamocortical pathways by structural or metabolic derangement and deafferentation. Electroencephalogram (EEG) patterns may be more varied in comatose children (alpha, theta, spindle and beta frequencies), possibly because of the difference in the response of the immature brain to such deafferentation. The term rhythmic coma pattern has been applied to these four patterns. ${ }^{8}$

From the Division of Neurology, Department of Paediatrics, The Hospital for Sick Children, University of Toronto, Toronto, Ontario, Canada .

ReCEIVED MARCh 7, 2005. ACCEPTED IN FINAL FORM MAY 27, 2005. Reprint requests to: Miguel A Cortez, Division of Neurology, The Hospital for Sick Children, University of Toronto, 555 University Avenue, Toronto, Ontario, Canada M5G 1 X8. 
This study had three objectives. 1. To determine the prevalence of rhythmic coma patterns in comatose children. 2. To compare the outcome in AC patterns and other rhythmic coma patterns. 3. To study the prognostic value of reactive rhythmic coma patterns.

\section{METHODS}

\section{Patients}

Children who had at least one EEG recording in the comatose state were included. A data abstraction form was used to review the clinical details including age and gender of patients, onset and cause of coma, drug treatment, time of EEGs, neuroimaging findings, follow-up and outcome. Children with pre-existing developmental delay and neurological deficits were excluded from the study. Modified James' Glasgow Coma Scale score was used to define coma. ${ }^{17}$

\section{EEG recordings}

All EEG recordings performed in comatose children between the ages of two months and 18 years at the Hospital for Sick Children, Toronto during the period of July 1996 to June 2003 were analyzed retrospectively. Electroencephalograms were recorded using the International 10-20-electrode placement system with 10-mm Grass Gold plated disc electrodes and paste application. Electrode impedance ranged from 1000- $5000 \mathrm{ohms}$. All EEGs were recorded using either the Stellate-Rhythm version 9.0 digital software (Montreal, Quebec) before 1999 or XLTEK-Neuroworks version 3.3 digital software (Oakville, Ontario) from 1999 onwards. Thirty-minute digital recordings were done at a sampling rate of $200 \mathrm{~Hz}$ with an open-ended band pass using Pz' electrode (which is located $1 \mathrm{~cm}$ posterior to $\mathrm{Pz}$ ) as a reference. The minimum vertical resolution used was 12 bits or better. All our EEG recordings conformed to the Canadian EEG standards. ${ }^{18,19}$

\section{Variables evaluated}

A staff neurophysiologist (MAC), blinded to the clinical information, analyzed all EEG recordings to determine the dominant frequency, voltage, reactivity, and any occurrence of epileptiform discharges and rhythmic patterns.

Reactivity was defined as a change in the frequency or voltage, time locked to passive eye opening or closure, auditory or painful stimuli. Alpha, beta, spindle and theta frequencies, which persisted for more than $50 \%$ of the record, were defined as rhythmic coma patterns. Alpha frequency pattern with no reactivity was classified as complete AC. Incomplete AC was defined as the reactive pattern. Follow-up EEGs during the period of coma were analyzed in the same manner. The EEG's performed when the child was out of coma were not analyzed. For this study we used the classification by Young et al. ${ }^{20}$ Subcategorizing rhythmic patterns (original category IV) to 'reactive' and 'non-reactive' groups modified Young's classification.

\section{Clinical outcome score system}

Clinical outcome was scored from 1 to 6 according to the Paediatric Cerebral and Overall Performance Category Scale (PCOPCS) (Scores 1-6; 1- normal, 2- mild disability, 3- moderate disability, 4- severe disability, 5- coma or vegetative state, 6- brain death). ${ }^{21}$ The PCOPCS score was ascertained by the clinical data recorded by the treating physician at the last available follow-up or at one year (whichever was earlier). The PCOPCS outcome was 'favourable' when the score was 3 or less. The PCOPCS outcome was 'unfavourable' if the score was higher than 3 .

\section{Statistical analysis}

Fisher's exact test and Mann-Whitney rank sum test were used to determine whether children with reactive rhythmic coma pattern had better outcome and to compare the outcome of other rhythmic coma patterns with that of AC; with the probability value of p. $<0.05$ chosen as an index of statistical significance.

\section{RESULTS \\ Prevalence of rhythmic coma patterns}

Sixty-eight comatose patients were identified during the study period. Thirty children were excluded from analysis due to insufficient clinical information, poor coma scoring or preexisting neurological deficits. Thirty-eight patients, who satisfied the inclusion criteria were analysed. Sixty-three EEGs in these 38 patients were interpreted. Nineteen $(30.2 \%)$ records in 14 patients showed rhythmic patterns ( $9 \mathrm{AC}, 4$ spindle coma, 4 theta coma and 2 beta coma). Five patients had two records each with a rhythmic coma pattern (patients 1, 2, 4, 7, 13). There were ten boys and four girls aged two months to 15 years (Mean age $\pm \mathrm{SD}=7.8 \pm 4.5$ ). Sixteen patients had at least two records during their hospital admissions.

As indicated in Table 1A, AC pattern was noticed from the first 24 hours to as late as 27 days after the onset of coma $(n=$ 9). However, in $55 \%$ of patients, AC pattern was noticed in the first week. Patients \#2 and \#9 had shown polymorphic delta activity in the first EEG. Six children with AC pattern had at least one follow-up EEG. In three children (50\%) polymorphic theta activity replaced the alpha frequency. Residual alpha frequency was not seen in the follow-up EEGs of these six children. Alpha frequency was diffusely distributed in all the cases. In one case, the AC pattern (Figure 1) was completely replaced by beta coma pattern (Figure 2) within 24 hours (patient 4). Other rhythmic patterns were spindle coma (Figure 3$)(n=4$, patients 10-13), theta coma $(n=4$; patients $1,2,7,13)$ and beta coma ( $n=2$, patients 4 and 14) (Table 1B). All these patterns appeared early (median- three days) after the onset of coma. There was no difference in the outcome associated with AC patterns or these patterns (Fisher's exact test, $\mathrm{p}=0.39$; MannWhitney $\mathrm{p}=0.6$ ) (Table 2).

\section{Rhythmic coma pattern reactivity}

Rhythmic coma pattern was reactive in nine records (seven children). Of the reactive EEGs, 66.7\% (6/9) were associated with favourable outcome. Two children (three records) had complete neurological recovery. Ten records (in seven children) showed non-reactive pattern. Sixty percent of the non-reactive records were associated with unfavourable outcome. No child with non-reactive pattern had normal neurological status on follow up. On statistical analysis, reactive patterns did not predict lower PCOPCS score (Mann-Whitney test; z-value of 
Table 1A: Alpha coma patterns

\begin{tabular}{|c|c|c|c|c|c|c|c|c|c|c|c|c|c|}
\hline \multirow[b]{2}{*}{ ż } & \multirow[b]{2}{*}{ 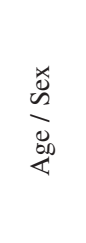 } & \multirow[b]{2}{*}{ 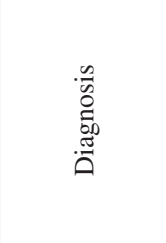 } & \multicolumn{5}{|c|}{ Alpha frequency patterns } & \multicolumn{3}{|c|}{ Follow-up EEG } & \multirow[b]{2}{*}{$\begin{array}{l}\infty 00 \\
\stackrel{\Xi}{\Xi 0} \\
\Xi \\
\Xi\end{array}$} & \multirow[b]{2}{*}{$\begin{array}{l}0 \\
7 \\
1 \\
0 \\
0 \\
0 \\
1 \\
1\end{array}$} & \multirow[b]{2}{*}{ 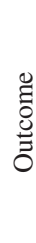 } \\
\hline & & & $\vec{\Xi}$ & 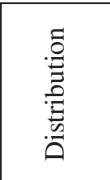 & 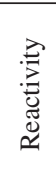 & 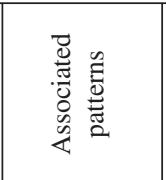 & 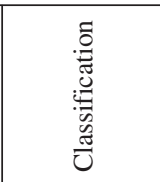 & $\overrightarrow{\tilde{\Xi}}$ & E & 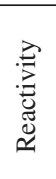 & & & \\
\hline 1 & $8 / \mathrm{M}$ & $\mathrm{HE}$ & 2 & Diffuse & No & $\begin{array}{l}\text { Intermittent } \\
\mathrm{PD} \text { and } \mathrm{PT}\end{array}$ & $\begin{array}{l}\text { Complete } \\
\text { AC pattern }\end{array}$ & 5 & $\mathrm{TC}$ & No & Diffuse Hypoxic edema & $12 \mathrm{mo}$ & 3 \\
\hline 2 & $7 / \mathrm{F}$ & $\begin{array}{c}\text { Status } \\
\text { epilepticus }\end{array}$ & 27 & Diffuse & No & $\mid \begin{array}{c}\text { Intermittent } \\
\text { PT }\end{array}$ & $\begin{array}{l}\text { Complete } \\
\text { AC pattern }\end{array}$ & 37 & $\mathrm{TC}$ & No & $\begin{array}{c}\text { Bilateral BG hyper-intense } \\
\text { signals in MR }\end{array}$ & $11 \mathrm{mo}$ & 4 \\
\hline 3 & $5 / \mathrm{M}$ & $\mathrm{HE}$ & 2 & Diffuse & No & \begin{tabular}{|} 
Intermittent \\
PD
\end{tabular} & $\begin{array}{c}\text { Complete } \\
\text { AC pattern }\end{array}$ & - & - & - & Diffuse Hypoxic edema & $6 \mathrm{mo}$ & 6 \\
\hline 4 & $15 / \mathrm{F}$ & $\mathrm{HE}$ & 3 & Diffuse & Yes & \begin{tabular}{|} 
Intermittent \\
$\mathrm{PD}$
\end{tabular} & $\begin{array}{l}\text { Incomplete } \\
\text { AC pattern }\end{array}$ & 4 & $\begin{array}{l}\text { Beta } \\
\text { coma }\end{array}$ & No & Diffuse Hypoxic edema & 11 days & 6 \\
\hline 5 & $3 / \mathrm{M}$ & Head Injury & 10 & Diffuse & Yes & $\begin{array}{c}\text { Intermittent } \\
\mathrm{PD}\end{array}$ & $\begin{array}{l}\text { Incomplete } \\
\text { AC pattern }\end{array}$ & - & - & - & $\begin{array}{l}\text { Diffuse hemorrhagic } \\
\text { contusions }\end{array}$ & $9 \mathrm{mo}$ & 3 \\
\hline 6 & $5 / \mathrm{M}$ & $\begin{array}{l}\text { Hepatic } \\
\text { coma }\end{array}$ & 7 & Diffuse & No & \begin{tabular}{|} 
Intermittent \\
$\mathrm{PD}$
\end{tabular} & \begin{tabular}{|l} 
Complete \\
AC pattern
\end{tabular} & 8 & PD & No & Diffuse cerebral edema & 10 days & 6 \\
\hline 7 & $15 / \mathrm{M}$ & Head Injury & 11 & Diffuse & Yes & \begin{tabular}{|} 
Intermittent \\
PD
\end{tabular} & $\begin{array}{l}\text { Incomplete } \\
\text { AC pattern }\end{array}$ & 15 & $\mathrm{TC}$ & Yes & $\begin{array}{l}\text { Diffuse hemorrhagic } \\
\text { contusions }\end{array}$ & $12 \mathrm{mo}$ & 3 \\
\hline 8 & $7 / F$ & Encephalitis & 1 & Diffuse & Yes & $\begin{array}{c}\text { Intermittent } \\
\text { PD }\end{array}$ & $\begin{array}{l}\text { Incomplete } \\
\text { AC pattern }\end{array}$ & - & - & - & $\begin{array}{l}\text { Bilateral frontal hyper- } \\
\text { intensity in MR }\end{array}$ & $12 \mathrm{mo}$ & 1 \\
\hline 9 & $9 / \mathrm{M}$ & $\begin{array}{c}\text { Status } \\
\text { epilepticus }\end{array}$ & 15 & Diffuse & No & \begin{tabular}{|} 
Intermittent \\
PD
\end{tabular} & $\begin{array}{l}\text { Complete } \\
\text { AC pattern }\end{array}$ & 16 & BS & NT & Diffuse Hypoxic edema & 30 days & 6 \\
\hline
\end{tabular}

M-male, F-female, PD \& PT - polymophic delta \& theta, AC - alpha coma, TC - theta coma, mo-months, BG - basal ganglia, MR - magnetic resonance, HE - hypoxic encephalopathy, BS - burst suppression, NT - not tested

Table 1B: Other rhythmic coma patterns

\begin{tabular}{|c|c|c|c|c|c|c|c|c|c|c|c|c|c|}
\hline \multirow[b]{2}{*}{$\stackrel{\circ}{z}$} & \multirow[b]{2}{*}{$\frac{\varpi}{0}$} & \multirow[b]{2}{*}{ 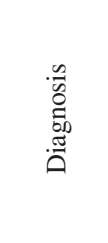 } & \multicolumn{5}{|c|}{ Other rhythmic patterns } & \multicolumn{3}{|c|}{ Follow-up EEG } & \multirow[b]{2}{*}{ 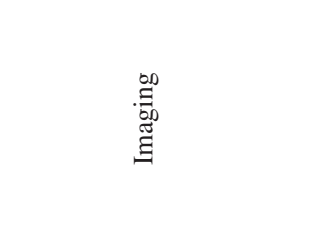 } & \multirow[b]{2}{*}{ 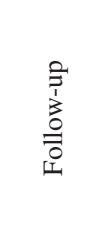 } & \multirow[b]{2}{*}{$\begin{array}{l}\stackrel{\Xi}{0} \\
\stackrel{0}{0} \\
0\end{array}$} \\
\hline & & & હે & 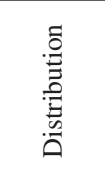 & 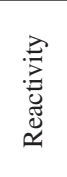 & 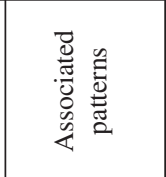 & 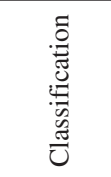 & હેّ & & 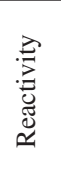 & & & \\
\hline 10 & $5 / \mathrm{F}$ & $\begin{array}{l}\text { Raised } \\
\text { ICP }\end{array}$ & 1 & Diffuse & Yes & $\begin{array}{c}\text { Intermittent } \\
\text { PD }\end{array}$ & $\begin{array}{c}\text { Spindle } \\
\text { Coma }\end{array}$ & - & - & - & Hydrocephalus & 5 days & 6 \\
\hline 11 & $2 \mathrm{mo} / \mathrm{M}$ & $\mathrm{HE}$ & 1 & Diffuse & No & Nil & $\begin{array}{c}\text { Spindle } \\
\text { Coma }\end{array}$ & - & - & - & Diffuse Hypoxic edema & $12 \mathrm{mo}$ & 2 \\
\hline 12 & $13 / \mathrm{M}$ & $\mathrm{HE}$ & 1 & $\begin{array}{l}\text { Fronto- } \\
\text { central }\end{array}$ & Yes & Nil & $\begin{array}{c}\text { Spindle } \\
\text { Coma }\end{array}$ & - & - & - & Diffuse Hypoxic edema & 5 days & 6 \\
\hline 13 & $9 / \mathrm{M}$ & $\mathrm{HE}$ & 1 & $\begin{array}{l}\text { Fronto- } \\
\text { central }\end{array}$ & Yes & Nil & $\begin{array}{c}\text { Spindle } \\
\text { Coma }\end{array}$ & 7 & $\mathrm{TC}$ & Yes & Diffuse Hypoxic edema & $11 \mathrm{mo}$ & 1 \\
\hline 14 & $1 / \mathrm{M}$ & $\mathrm{HE}$ & 2 & Diffuse & No & Nil & $\begin{array}{l}\text { Beta } \\
\text { Coma }\end{array}$ & - & - & - & Diffuse Hypoxic edema & 12 & 3 \\
\hline
\end{tabular}

M-male, F-female, PD - polymophic delta, TC - theta coma, mo-months, HE - hypoxic encephalopathy, ICP - intra-cranial pressure 
Table 2: Comparison of Alpha coma patterns and other rhythmic coma patterns

\begin{tabular}{l|l|l}
\hline Variable & Alpha coma pattern & Other rhythmic coma patterns \\
\hline Number of records & 9 & 10 \\
\hline Onset in days (Median) & 7 & 3 \\
\hline Etiology & & \\
\hline Hypoxia & 3 & 7 \\
\hline Head injury & 2 & 1 \\
\hline Status epilepticus & 2 & 1 \\
\hline Raised ICP & - & 1 \\
\hline Others & 2 & - \\
\hline Mean coma score & 6.5 & 7 \\
\hline Outcome associated with the pattern & & \\
\hline Mean PCOPCS score & 4.2 & 3.5 \\
\hline Unfavorable & 5 & 4 \\
\hline Death & 4 & 3 \\
\hline Normal & 1 & 2 \\
\hline
\end{tabular}

NB- 14 patients had these 19 records. 4 patients (\# 1, 2, 4, 7 in Table 1 A are included in both groups as their first EEG showed AC pattern and second EEG showed other rhythmic coma pattern, patient \#13 had spindle coma pattern in the first and theta coma pattern in the second EEG). ICP = intracranial pressure.

difference $=-1.1, \mathrm{p}=0.14$ ) or a favourable outcome (Fisher's exact test $\mathrm{p}=0.19$ )

\section{DisCUSSION}

Rhythmic coma patterns were found in $30.2 \%$ of recordings. To date this is the largest paediatric series analysing rhythmic coma patterns in children and clinical outcome. Only 19 cases of $\mathrm{AC}$ pattern had been reported in the paediatric population. ${ }^{1-11}$ Westmoreland defined AC pattern as the occurrence of persistent and 'unreactive' alpha $(8-13 \mathrm{~Hz})$ frequency as the principal electroencephalographic feature in comatose patients. ${ }^{1}$ Subsequently, other authors have accepted reactive patterns as

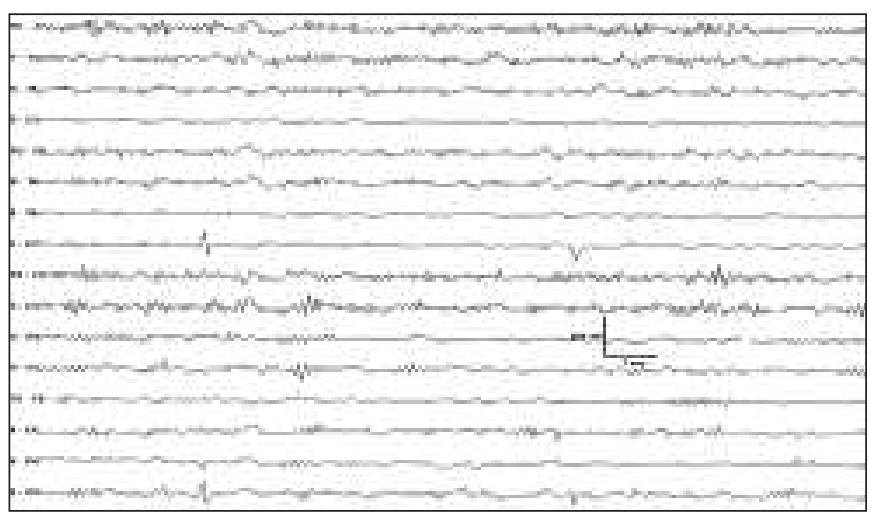

Figure 1: Alpha coma. Anterior-Posterior (AP) bipolar montage shows anteriorly dominant monotonous alpha frequency. Intermittent theta slowing and rate right temporoparietal sharp waves are also seen.
AC pattern. ${ }^{12,13,15}$ Reactivity is defined as a change in the frequency and or voltage of the background frequency to external stimuli. ${ }^{15} \mathrm{AC}$ pattern is a transient pattern. Follow up EEGs were available in six cases of AC. After an interval of 110 days (mean 3.3 days), AC was completely replaced by other patterns ( 3 theta coma, 1 polymorphic delta, 1 burst-suppression and 1 beta coma).

Chatrian had observed the co-existence of AC and TC in the same recording. ${ }^{14}$ This pattern was termed alpha-theta coma by Young et al, suggesting that there may be little essential difference between $\mathrm{AC}$ and $\mathrm{TC}$, in terms of pathogenesis, aetiology and prognostic significance. There was intermittent theta activity along with AC pattern in two tracings. In three

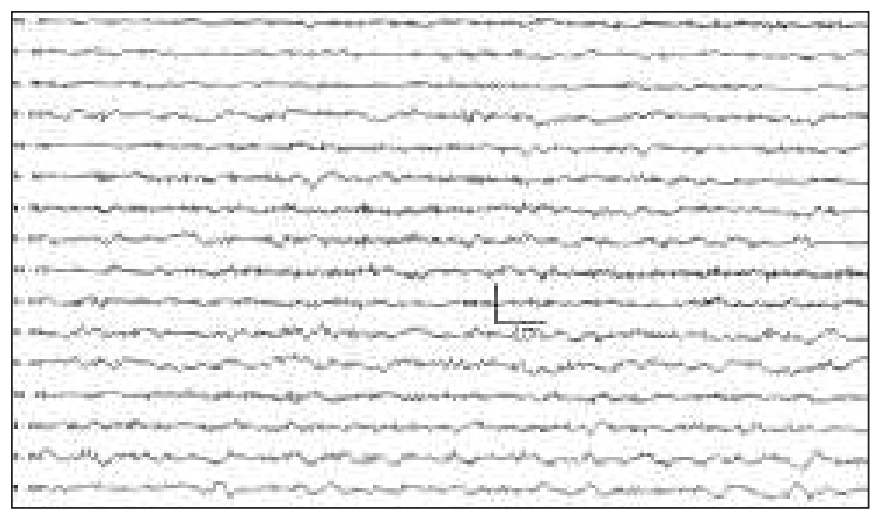

Figure 2: Beta coma. Anterior-Posterior (AP) bipolar montage shows diffuse beta frequency. 
cases, AC pattern subsequently evolved into theta coma. This observation on a small number of tracings supports Young's ${ }^{13}$ theory in paediatric EEGs as well.

The value of postanoxic $\mathrm{AC}$ or $\mathrm{TC}$ in predicting the outcome is controversial. In a review of adult literature, Berkhoff et al ${ }^{12}$ found that $33(12 \%)$ of 283 patients with postanoxic AC survived, 16 of whom; had only minimal or no residual cognitive deficits. A review of 335 reported cases of AC that included aetiology and outcome showed a mortality of $76 \% .{ }^{15}$ Young et $\mathrm{al}^{13}$ reported survival with regained consciousness in $13 \%$ of patients with AC, TC or alpha-theta coma. However, in children, of the 19 reported cases, ten $(52.6 \%)$ died, five had normal neurological status or returned to pre-event status and four had severe neurological deficits. Ten records with rhythmic coma pattern in our study was in children with hypoxic encephalopathy (HE). Mortality was $60 \%$. Only one child with $\mathrm{HE}$ had a normal neurological outcome. As in adults, survival was better if the cause of AC was drug toxicity, stroke or infection. One child with cyclosporin toxicity expired following a cardiac arrest. ${ }^{11}$ Our data also suggested that the outcome (in terms of mortality) of AC pattern in children was more positive as compared to the published adult data. Mortality associated with AC pattern in our series was $44.4 \% .^{4,9}$ Only one child with AC pattern had a normal neurological status on follow-up. Adult studies show that when AC followed a condition other than cardiac arrest or a brainstem lesion, the outcome was better. ${ }^{15}$ In our series, HE resulted in AC pattern in three children and two died. Numbers were too small to draw any conclusion; therefore further prospective studies are warranted.

The concept of rhythmic coma patterns in children was suggested by Horton et al. ${ }^{8}$ This included coma with alpha, theta, beta or spindle frequency. Aetiology, reactivity and outcome of spindle and beta coma were similar to AC or TC patterns in our study. In five patients one rhythmic pattern evolved into another rhythmic pattern. Hence, we also feel that these patterns should be considered together in EEG analyses of paediatric coma patterns. Eleven children with rhythmic coma patterns had been

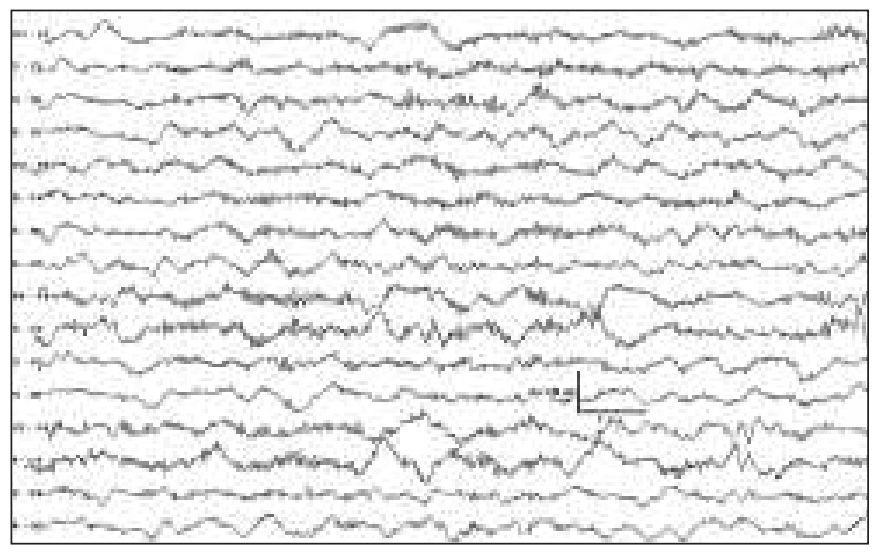

Figure 3: Spindle coma - Anterior-Posterior (AP) bipolar montage shows spindle activity mainly in the parasagittal area. detected in Childrens' Hospital of Los Angeles during a period of 12 months. ${ }^{8}$ We could find rhythmic coma patterns in $30.2 \%$ of the EEG recordings done in comatose children. These two reports clearly demonstrated that rhythmic coma patterns are not uncommon in the paediatric population.

There is evidence in the literature to indicate that incomplete AC pattern has a better prognosis in adults. ${ }^{12,13,15}$ In a study of 14 adult patients with postanoxic AC, all patients with complete AC died. Three out of five patients with incomplete AC survived. ${ }^{12}$ Fifteen of 36 tracings in Kaplan's series showed reactivity. Eight patients with incomplete (reactive) alpha pattern regained consciousness and the EEG reactivity correlated with survival. Only three of the 19 patients with a complete AC pattern regained consciousness. If the EEG showed no reactivity after HE, patients were likely to die. ${ }^{15}$ In our study, reactive pattern was associated with favourable outcome $(66.7 \%)$. Non-reactive rhythmic pattern was associated with unfavourable outcome (60\%). However, there was no statistically significant difference between the two groups in terms of favourable outcome or PCOPCS score. Small sample might have skewed the results.

Our study indicated that sequential EEG recordings are required to detect the evolution of rhythmic coma patterns during childhood. Only a few patients in our series had consecutive EEG recordings. Other limitations were the small sample size, variable timing of the EEG recording and exclusion of a significant number of patients due to strict inclusion criteria. Though neurological improvement in children had been documented for 1.5 to 5 years since the onset of coma, we used a short-term follow up of one year (maximum) for assigning the PCOPCS score. The PCOPCS is a well-validated scale in paediatric practice. ${ }^{21-23}$ However; it is not validated for long-term outcome. ${ }^{21}$ Hence for statistical analysis we used the PCOPCS score at one year or the last clinic visit (if it was before one year).

Rhythmic coma patterns are not uncommon in comatose children. Rhythmic coma patterns are part of a distinct category as reported in the adult EEG with reproducible aetiology, reactivity and outcome measures. Further prospective multicentre collaborative studies are warranted to ascertain the prognostic significance of reactive coma patterns in children. A careful determination of EEG reactivity is indicated in all comatose children presenting with rhythmic coma patterns, to establish the prognostic value of EEG.

\section{ACKNOWLedgments}

We thank the RET Technologists for the care taken in the EEG recordings and to Marilyn McLaughlin for secretarial assistance.

\section{REFERENCES}

1. Westmoreland BF, Klass DW, Sharbrough FW, Reagan TJ. Alphacoma. Electroencephalographic, clinical, pathologic, and etiologic correlations. Arch Neurol 1975; 32: 713-718.

2. Lersch DR, Kaplan AM. Alpha-pattern coma in childhood and adolescence. Arch Neurol 1984; 41: 68-70.

3. Yamada T, Stevland N, Kimura J. Alpha-pattern coma in a 2-yearold child. Arch Neurol 1979; 36: 225-227.

4. Homan RW, Jones MG. Alpha-pattern coma in a 2-month-old child. Ann Neurol 1981; 9: 611-613.

5. Pulst SM, Lombroso CT. External ophthalmoplegia, alpha and spindle coma in imipramine overdose: case report and review of the literature. Ann Neurol 1983; 14: 587-590. 
6. Sorensen K, Thomassen A, Wernberg M. Prognostic significance of alpha frequency EEG rhythm in coma after cardiac arrest. Neurol Neurosurg Psychiatry 1978; 41: 840-842.

7. Molofsky WJ. Alpha coma in a child. J Neurol Neurosurg Psychiatry 1982; 45: 95.

8. Horton EJ, Goldie WD, Baram TZ. Rhythmic coma in children. Child Neurol 1990; 5: 242-247.

9. Frisher S, Herishanu Y. Mu and alpha rhythm in comatose children. Childs Nerv Syst 1985; 1: 208-210.

10. Collins AT, Chatrian GE. EEG rhythm of alpha frequency in a 22month-old child after strangulation. Neurology 1980; 30: 13161319.

11. Sarma GR, Kumar A, Roy AK, Pinheiro L. Post-cardiorespiratory arrest beta-alpha coma: an unusual electroencephalographic phenomenon. Neurol India 2003; 51: 266-268.

12. Berkhoff M, Donati F, Bassetti C. Postanoxic alpha (theta) coma: a reappraisal of its prognostic significance. Clin Neurophysiol 2000; 111: 297-304.

13. Young GB, Blume WT, Campbell VM, et al. Alpha, theta and alphatheta coma: a clinical outcome study utilizing serial recordings. Electroencephalogr Clin Neurophysiol 1994; 91: 93-99.

14. Chatrian GE. Coma, other states of altered responsiveness and brain death. In: Daly DD, Pedley TA, (Eds.) Current practice of Clinical Electroencephalography. New York:Raven Press, 1990: 442.
15. Kaplan PW, Genoud D, Ho TW, Jallon P. Etiology, neurologic correlations, and prognosis in alpha coma. Clin Neurophysiol 1999; 110: 205-213.

16. Austin EJ, Wilkus RJ, Longstreth WT Jr. Etiology and prognosis of alpha coma. Neurology 1988; 38: 773-777.

17. Tatman A, Warren A, Williams A, Powell JE, Whitehouse W. Development of a modified paediatric coma scale in intensive care clinical practice. Arch Dis Child 1997; 77: 519-521.

18. Task Force of The Canadian Society of Clinical Neurophysiologists. Minimal standards for electroencephalography in Canada. Can J Neurol Sci 2002; 29: 216-220.

19. Blume WT. Canadian EEG standards: a quality issue. Can J Neurol Sci 2002; 29: 205.

20. Young GB, McLachlan RS, Kreeft JH, Demelo JD. An electroencephalographic classification for coma. Can J Neurol Sci 1997; 24: 320-325.

21. Fiser DH. Assessing the outcome of pediatric intensive care. $\mathrm{J}$ Pediatr 1992; 121: 68-74.

22. Mandel R, Martinot A, Delepoulle F, et al. Prediction of outcome after hypoxic-ischemic encephalopathy: a prospective clinical and electrophysiologic study, J Pediatr 2002; 141: 45-50.

23. Carter BG, Taylor A, Butt W. Severe brain injury in children: longterm outcome and its prediction using somatosensory evoked potentials (SEPs), Intensive Care Med 1999; 25: 722-728. 